\title{
A FORMA-CÍDIO E SUAS ARTICULAÇÕES MORFOLÓGICAS SOB O PONTO DE VISTA DA ENUNCIAÇÃO
}

\section{Thalita Nogueira Dias* \\ UFMG}

Resumo: Este artigo desenvolve um estudo semântico da forma -cídio, advindo do latim "cid/um" (ação de quem mata ou o seu resultado). Estudamos as articulações morfológicas " $x$-cídio" homicídio, infanticídio, suicídio, feminicídio, generocídio, lesbocídio, sincericídio, politicídio, encontradas em sites da web. Analisamos essas construções pela perspectiva dos conceitos teóricos da semântica da enunciação formulados por Dias (2018). Os resultados da análise demonstram que as construções " $x$-cídio" adquirem relevância como morte provocada, com diferentes direcionamentos de sentidos e motivadas por fatores sociais, jurídicos e políticos, ideologicamente determinados.

Abstract: This paper develops a semantic study of the form "-cidio," coming from the Latin "cid / um" (action of who kills or its result). We study the morphological articulations " $x$-cídio" homicídio, infanticídio, suicídio, feminicídio, generocídio, lesbocídio, sincericídio, politicídio, found in web sites. We analyze these constructions from the perspective of the theoretical conceptions of the semantics of enunciation formulated by Dias (2018). The results of the analysis show that " $x$-cidio" constructions acquire relevance as provoked death, with different orientations of meanings and motivated by ideologically determined social, juridical, and political factors.

\section{Introdução}

Este texto desenvolve um estudo sobre a formação de palavras a partir do ponto de vista da semântica da enunciação. No âmbito desse campo, procuramos responder a seguinte pergunta: como essa perspectiva teórica pode explicar a formação de palavras, em especial, com a forma -cídio? Isto é, quais são as razões enunciativas para que a (cc) EY-NC-SA

Líng. e Instrum. Linguíst., Campinas, SP, n. 44, p. 57-77, jul./dez. 2019 


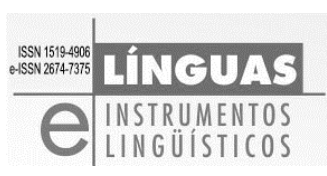

forma -cídio integre palavras como "homicídio", "feminicídio" e "politicídio"?

Para responder essa questão, organizamos este trabalho em quatro partes. Na primeira, abordamos aspectos da composição nominal em estudos morfológicos de cunho cognitivistas com enfoque para composições neoclássicas com o radical -cídio. Na segunda parte, apresentamos os conceitos teóricos da semântica da enunciação com qual trabalhamos, em contraponto à visão cognitivista sobre a composição nominal. Na terceira parte, descrevemos a metodologia de redes enunciativas, bem como a organização da análise das ocorrências de x-cídio ("homicídio, infanticídio, suicídio, feminicídio, generocídio, lesbocídio, sincericídio, politicídio") coletadas em portais de notícias em corpora eletrônicos. Na quarta parte, desenvolvemos as análises das formações $\mathrm{x}$-cídio, dispostas em amostras de redes enunciativas. Por fim, expomos o resultado de nossas análises defendendo que, com o ponto de vista teórico da semântica da enunciação, podemos explicar, de maneira eficaz, o funcionamento social das articulações nominais, sejam elas "neoclássicas", sejam elas neologismos.

\section{A composição nominal em estudos morfológicos cognitivistas: o radical -cídio}

Os compostos nominais formados com o radical -cídio são chamados de neoclássicos, no âmbito dos estudos morfológicos. Conforme Gonçalves (2016), os compostos neoclássicos são constituídos por radicais de bases presas de origem greco-latina utilizados, geralmente, na linguagem técnico-científica e filosóficoliterária. No entanto, o autor observa que tem ocorrido o aparecimento de novos compostos neoclássicos, como a palavra "sincericídio", cunhados por analogia a termos já em funcionamento na língua, como "homicídio" e "genocídio". Para ele, essa tendência mostra que radicais como esse, têm desempenhado papel de afixo, pois possuem uma função semântico-sintática definida, ou seja, os compostos xcídio são formadores de palavras com significado de morte.

Conforme Bybee (2010), a formação de novos compostos pode ser explicada por meio de uma rede de associações, isto é, pelo reconhecimento de paridades semânticas e/ou fonéticas entre diferentes palavras, o que permite o alcance a constituintes da

Líng. e Instrum. Linguíst., Campinas, SP, n. 44, p. 57-77, jul./dez. 2019 
construção sem que a palavra seja extensamente analisada em morfemas. Conforme essa proposição, a formação de novos compostos com x-cídio ocorre por analogia, isto é, a forma -cídio, armazenada na memória do falante, é ativada em novas construções com semelhanças fonéticas e semânticas. Portanto, é possível dizer, conforme essa visão, que o aparecimento da palavra "feminicídio" decorre por analogia à palavra "homicídio".

Autores como Almeida, Andrade e Gonçalves (2010, p.4) argumentam ainda que construções com o radical -cídio devem ser analisadas por meio do processo morfológico denominado "substituição sublexical" (SSLs), o qual, de acordo com a semântica cognitiva, caracteriza-se "por apresentar nova perspectiva sobre a entidade que está sendo instanciada". Nesse sentido, em conformidade com a concepção desses autores, o -cídio estaria passando por um processo de morfologização, adquirindo, assim, o status de sufixo.

Observando esses estudos, argumentamos que a explicação que pretendemos desenvolver sobre o processo de formação de palavras com a forma -cídio, não está ligada apenas à concatenação desse radical a formas do latim, do grego ou vernáculas, ou ainda a uma rede associativa analógica de construção semântica e fonética, e nem ao processo de substituição sublexical que resulta na mudança de estatuto da forma -cídio, de radical para sufixo.

Estudamos a formação de palavras pela perspectiva da semântica da enunciação, trabalhando com a concepção teórica de referencial histórico e pertinência enunciativa (DIAS, 2018). Esses conceitos permitem compreender a formação de novas palavras a partir do acontecimento de enunciação. Com isso, podemos mostrar como ocorre a relação enunciativa entre diferentes bases-x e a forma -cídio. Ou seja, não basta a composição morfológica entre base e -cídio em si mesmo: "homo+cídio" = "homicídio". Por isso, buscamos no enunciado as determinações semântico-enunciativas da articulação nominal x-cídio, isto é, as pertinências enunciativas que possibilitam a articulação nominal pela participação de diferentes bases frente à forma -cídio, a qual guarda um referencial histórico definido.

\section{Fundamentação teórica: a semântica da enunciação}

Líng. e Instrum. Linguíst., Campinas, SP, n. 44, p. 57-77, jul./dez. 2019 
Os fundamentos teóricos deste artigo estão voltados para uma abordagem semântica, de natureza enunciativa, que teve sua origem na França por meio das teses de Bally (1947), Benveniste (1966;1970) e Ducrot (1984). As perspectivas teóricas desses autores sobre a enunciação diferem entre si, mas mantêm a concepção geral de que o estudo da significação deve envolver o processo de constituição de sentidos. Na visão de Bally, esse processo se dá pela presença inerente de um modus no dictum. Para Benveniste, situa-se na passagem da língua ao discurso. Por fim, em Ducrot, a constituição dos sentidos é determinada pelo acontecimento da produção do enunciado. Dentre essas perspectivas, vamos nos concentrar numa leitura específica do conceito de acontecimento a partir de Ducrot, com vistas ao nosso propósito.

No Brasil, Guimarães (2005) reformula o conceito de acontecimento, elaborado por Ducrot, para desenvolver uma abordagem enunciativa que considera a enunciação como um acontecimento de linguagem que se faz pelo funcionamento da língua. Essa visão produz diferenças em relação ao ponto de vista ducrotiano. Para Guimarães $(2005$, p.11, 12) "o acontecimento não é um fato no tempo, o acontecimento instala a sua própria temporalidade". Assim, algo que é enunciado no presente só significa porque projeta um futuro de sentidos, tendo em vista um memorável de enunciados anteriores.

Ainda no Brasil, Dias (2018, p. 12, 251, 253, 254) retoma o conceito de acontecimento numa abordagem da enunciação voltada para o estudo das relações linguísticas. A necessidade de trabalhar a língua nas suas relações de ordem gramatical, numa visão enunciativa, exigiu especificidades no conceito de acontecimento. Nesse sentido, Dias defende que o acontecimento de produção do enunciado se constitui na relação entre uma demanda do presente do enunciar e memoráveis de outros enunciados, e propõe duas concepções teóricas vinculadas a esse conceito: referencial histórico e pertinência enunciativa, os quais orientam o conceito de acontecimento para uma abordagem das relações de organicidade da língua, numa dimensão enunciativa.

Dias (2018) explica que faz parte do referencial histórico tudo o que as palavras ou sintagmas nos conduzem a perceber, imaginar e acreditar, seja no meio em que nos situamos, em termos de objetos,

Líng. e Instrum. Linguíst., Campinas, SP, n. 44, p. 57-77, jul./dez. 2019 
pessoas e situações, seja no universo das crenças, do imaginário, dos conceitos em geral, ou seja,

o dizer se faz pertinente nas práticas de linguagem cotidianas quando uma demanda do presente produz relação com memoráveis de outros dizeres. [...] esse memorável de outros dizeres, constituídos na instância do "já enunciado", são parte desse referencial histórico, isto é, desses domínios de ancoragem do enunciado, tendo em vista o funcionamento histórico-social. (DIAS, 2018, p. 101-102).

O conceito de referencial histórico tem inspiração na diferença, estabelecida por Foucault, entre referência e referencial ${ }^{1}$. Nessa direção, Dias (2018, p.99) argumenta que

[...] aquilo a que o enunciado se refere (referente), o que é "posto em jogo" por ele, não se situa apenas no "que é dito", mas também naquilo "de que fala". Essa diferenciação parece se assentar em um fio bastante tênue. No entanto, ela abriga um potencial bem interessante, quando se trata de abordar a relação entre linguagem e exterioridade do ponto de vista da enunciação. [...] pela expressão "de que fala", Foucault considera os domínios em relação aos quais palavras ou sintagmas significam, não pelas singularidades do que elas dizem, mas por relações que o enunciado que as absorve estabelece. Essas relações formariam um domínio de referências, ou simplesmente referencial.

Considerando o referencial histórico, as palavras também significam, conforme Dias (2016, p. 38), pela "pertinência enunciativa contraída em determinado espaço de enunciação". Assim, o conceito de pertinência não tem a ver com dizer algo adequado a uma determinada situação, mas sim com a possibilidade de projeção do dizer no espaço de enunciação. Nessa direção, Dias (2016, p.37) denomina de pertinência enunciativa "a relação que um enunciado mantém com os determinantes da enunciação em atualidade, incluindo-se outros enunciados do presente do enunciar”.

Líng. e Instrum. Linguíst., Campinas, SP, n. 44, p. 57-77, jul./dez. 2019 


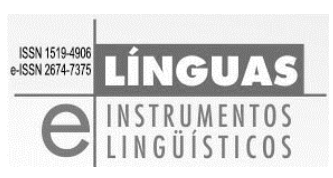

Nesse sentido, o conceito de pertinência enunciativa também se assenta na ideia de adesão, pois conforme Dias (2018, p. 103),

enquanto seres de linguagem, vale dizer, enquanto seres constitutivamente históricos, nós somos instados a responder, a interpretar, a interferir enunciativamente nas situações que se nos apresentam. É a "demanda do presente" que estamos denominando pertinência enunciativa. As respostas, as interpretações, as interferências que se efetivam na enunciação, isto é, as respostas às demandas do presente são constitutivas do acontecimento enunciativo.

Os conceitos denominados "referencial histórico" e "pertinência enunciativa" permitem trabalhar a nominalidade a partir de uma visão enunciativa, consubstanciada pelo conceito de formação nominal (FN), o qual incide sobre o processo enunciativo de formação de palavras e não sobre o processo cognitivo como no caso da composição nominal. Dias (2018b, p.262) considera, assim, que a significação de uma FN é dada pela relação entre o referencial e a pertinência, e que

essas são especificamente as condições que fundam a articulação entre os termos nas formações nominais, isto é, que fundam os diferentes procedimentos de agregação no âmbito de uma formação nominal.

O conceito de formação nominal, nos termos Dias (2015a, p. 151), "constitui-se em um novo olhar para o 'sintagma nominal', um olhar configurado pela enunciação ${ }^{2 \%}$. Tendo em vista uma visão enunciativa, Dias explica que a FN

congrega nomes, designações, afirmações, mas concebidos não em termos informativos das entidades, mas a partir do campo de emergência das entidades nomeadas. Uma entidade exterior à linguagem precisa adquirir pertinência para ser nomeada, [...] Trata-se de um recorte enunciativo, porque essas entidades não se encontram discriminadas e delimitadas na natureza. A enunciação irá torná-las pertinentes aos acontecimentos

Líng. e Instrum. Linguíst., Campinas, SP, n. 44, p. 57-77, jul./dez. 2019 
linguísticos, tendo em vista as possibilidades históricas que as fazem emergir. (DIAS, 2013, p. 15).

Com esse olhar, é possível, segundo Dias (2018), passar do nível descritivo das relações sintagmáticas para o nível explicativo do funcionamento enunciativo da língua.

Nesse sentido, as FNs constituídas pela forma -cídio, que serão estudadas neste artigo, não denotam, a exemplo do que Dias (2018, p. 122) explica sobre a FN,

o produto da constituição de nomes compostos, como nos estudos morfológicos estruturalistas, e nem o produto de um corte sintagmático, propulsor do nome sintagma, mas a unidade nominal considerada a partir do processo de constituição dos nomes.

A articulação dessas FNs, numa visão enunciativa, ocorre por meio de um processo que o autor chama de articulação intranominal, em contraponto ao que a gramática chama de morfologia estrutural. Desse modo, considerando as razões de ordem enunciativa no processo de articulação, as FNs constituídas por articulação intranominal são formadas pelo esquema $x$-cídio, no qual x é ocupado, por exemplo, pelas bases "homo" e "sui" formando palavras como "homicídio" e "suicídio". Nesse sentido, Dias (2018, p.12) diz que

as razões enunciativas da constituição da formação nominal não prescindem das regularidades estruturais, mas estão centradas numa ordem da materialidade do dizer cujo alcance é mais amplo e denso do que a horizontalidade das relações sintagmáticas.

Para explicar o processo de formação de palavras por articulação intranominal, Dias (2018, p. 142) desenvolve, considerando o conceito de formação nominal, um estudo da articulação "entre o formante xmetro e uma base constituinte como "razão enunciativa" para a constituição do nome".

Líng. e Instrum. Linguíst., Campinas, SP, n. 44, p. 57-77, jul./dez. 2019 
$\mathrm{Na}$ análise desenvolvida por Dias, os conceitos de referencial histórico e pertinência enunciativa estabelecem a base da FN, e, por isso, também oferecem suporte para o estudo da articulação intranominal considerando não apenas a estrutura morfológica, mas as razões enunciativas de sua constituição.

Antes de passar para a análise das FNs x-cídio, constituídas por articulação intranominal, apresentamos, na sequência, a concepção metodológica formulada por Dias (2018).

\section{A concepção metodológica da análise: rede enunciativa}

Neste artigo, empregamos o procedimento operativo de ordem teórico-metodológico denominado "rede enunciativa", desenvolvido por Dias (2018, p. 35 e 36), para o qual

a constituição de uma rede enunciativa envolve a formação de contrastes entre a construção linguística em estudo e outras construções com estruturas semelhantes e palavras iguais, no sentido de permitir a percepção do valor semântico que a enunciação sustenta. Essas construções outras, trazidas para a rede enunciativa, são construídas pelo próprio pesquisador e também buscadas em usos efetivos, como no Google e nos bancos de dados que abrigam usos orais e escritos da nossa língua.

Nesse sentido, a rede enunciativa se mostra capaz de captar não só a estruturação morfológica, mas também a determinação da enunciação pelo enunciado, assim, uma rede enunciativa não é meramente uma comutação estrutural. Por isso, julgamos que a construção de redes enunciativas se mostra como um procedimento inovador para a realização de análise enunciativa de formas nominais, pois permite: visualizar a extensão enunciativa-morfológica das unidades linguísticas x-cídio; mostrar, com suporte no referencial histórico, as pertinências enunciativas que sustentam a articulação nominal de palavras com uso socialmente consolidado como "homicídio", e também de novas ocorrências como "politicídio" e "linguicídio".

Com base no procedimento metodológico das redes enunciativas, as FNs X-cídio que analisamos foram coletadas do Jornal O Estado de

Líng. e Instrum. Linguíst., Campinas, SP, n. 44, p. 57-77, jul./dez. 2019 
S. Paulo (acervo eletrônico), dos portais de notícias G1, UOL, Catraca livre e O Povo, ambos acessados através do Corpus do Português ${ }^{3}$, banco de dados eletrônico que concentra textos de portais da web.

Tendo em vista esse recorte, montamos amostras de redes enunciativas que apresentam FNs constituídas de x-cídio agrupadas em: (1) "homicídio", "infanticídio", "suicídio", (2) "feminicídio", "lesbocídio", "generocídio", (3) "sincericídio", "politicídio". A constituição dessas amostras tem como objetivo produzir organização metodológica para a análise, levando em conta, hipoteticamente, que cada grupo de FNs partilham do mesmo nicho de pertinências, observando, de acordo com Dias (2015b, p. 243), que o conceito de pertinência "é relativo à agregação de um enunciado [formação nominal] no espaço de enunciação, submetido a um referencial, e não tem relação com a qualidade da relação do enunciado nesse espaço".

Isso posto, observamos que o referencial histórico da forma -cídio não é constituído simplesmente por ser um radical latino provindo do verbo caedere (matar), o qual agrega o significante indicador de "morte" às formas nominais. Essa definição seria apenas um modo de referencia-lo morfologicamente. O que sustenta o referencial histórico da forma -cídio são as razões enunciativas que orientam as possibilidades de formulação de novas pertinências no acontecimento de enunciação.

Portanto, podemos dizer que a forma -cídio participa de FNs que designam finitude, tendo em vista o referencial histórico de "morte provocada", seja da vida humana (enquanto ação de quem mata ou o seu resultado) como em: "Um homem ainda não identificado cometeu uma série de homicídios"; "O morador de rua foi vítima de homicídio", ou ainda de entidades (enquanto mudança de paradigma que regulam o comportamento social) como em: "A fala de Paulinho é um típico sincericídio"; "Marcus tem ataque de sincericídio que renderá muitos comentários[...]".

Nesse sentido, quando agregado a diversas bases, a forma -cídio conduz a diferentes pertinências enunciativas no acontecimento de enunciação, como veremos a seguir na rede enunciativa 1, que apresenta as FNs "homicídio"," infanticídio" e "suicídio".

Líng. e Instrum. Linguíst., Campinas, SP, n. 44, p. 57-77, jul./dez. 2019 
5.Analise das formas x-cídio: referencial histórico e pertinências enunciativas

\subsection{Rede enunciativa 1: homicídio, infanticídio, suicídio}

(a) Mãe acusada de matar bebê e esconder corpo por 5 anos tem júri popular marcado, em Goiânia. [...] Ministério Público Estadual (MP-GO) pede que a ré seja condenada por homicídio duplamente qualificado, por motivo torpe e recurso que impossibilitou a defesa da vítima. [...] O advogado dela, [...]defende que o crime seja desqualificado para infanticídio, alegando que ela matou a filha motivada pela ocorrência de Psicose Puerperal, conhecida como Psicose Pós-Parto. (REZENDE, 2018, grifo nosso).

(b) Euler Fernando Grandolpho entrou na Catedral, abriu fogo contra fiéis no encerramento da missa, matou cinco pessoas e em seguida cometeu suicídio. [...] Segundo a polícia, o atirador fez tratamento contra depressão e a família temia que ele cometesse suicídio. (G1, 2018, grifo nosso).

O enunciado (a), que discorre sobre caso de uma mãe acusada de matar o próprio fillho, apresenta duas FNs: "homicídio" e "infanticídio". O referencial histórico de -cídio, ao compor a base "homo" em "homicídio", estabelece pertinência enunciativa de "morte provocada" de seres humanos, já em "infanticídio" ("infans +cídio"), a pertinência enunciativa se dá pelas enunciações que dizem da "morte provocada" de recém-nascidos. Portanto, embora "homicídio" e "infanticídio" sejam intercambiáveis nesse acontecimento de linguagem, a relação de pertinência enunciativa não é equivalente.

Essa compreensão pode ser observada em (a):

Ministério Público Estadual (MP-GO) pede que a ré seja condenada por homicídio [...] $\mathrm{O}$ advogado dela, [...]defende que o crime seja desqualificado para infanticídio, alegando que ela [mãe] matou a filha motivada pela ocorrência de Psicose Puerperal, conhecida como Psicose Pós-Parto (grifo nosso).

Esse fragmento enunciativo mostra que essas FNs contraem pertinência enunciativa de "perda da vida humana", ou seja, podemos

Líng. e Instrum. Linguíst., Campinas, SP, n. 44, p. 57-77, jul./dez. 2019 
dizer que "infanticídio" sempre será um "homicídio", mas não será possível que o inverso sempre ocorra, ou seja, que um "homicídio" seja sempre um "infanticídio", dado que essa FN adquire novas relações de sentido no acontecimento. Diante disso, a projeção enunciativa de "infanticídio" passa pelo que Dias (2018, p.17) denomina domínio de mobilização, isto é, pelas "articulações de sentido socialmente configuradas que determinam as formas expressivas na constituição de uma unidade significativa".

$\mathrm{Ou}$ seja, a relação enunciativa entre as FNs "homicídio" e "infanticídio" é pertinente na medida em que estabelece uma relação de sentido com o enunciado no qual aparece. Nesse sentido, é possível observar no fragmento enunciativo (a) que a forma -cídio estabelece pertinência enunciativa por configurar socialmente o ato de matar ("homicídio") como morte criminosa de recém-nascido provocada pela condição psicológica da mãe, exposta nesse acontecimento, pelas FNs Psicose Puerperal e Psicose Pós-Parto, conjuntura que possibilita, por exemplo, em relação a homicídio, diferentes direcionamentos de sentidos dados pelas implicações jurídicas e sociais.

O enunciado (b) relata o caso de um homem que se matou após assassinar cinco pessoas. Essa ocorrência linguística apresenta a FN "suicídio", na qual a forma -cídio, ao se agregar a base "sui", condensa um memorável de enunciações que constitui a pertinência enunciativa de "suicídio" como "morte provocada", pelo ato voluntário de tirar a própria vida.

Nesse acontecimento enunciativo, a FN "suicídio" estabelece um encadeamento enunciativo com a FN "depressão" como é possível notar em (b): "o atirador fez tratamento contra depressão e a família temia que ele cometesse suicídio". Nesse sentido, o referencial de "suicídio" torna-se pertinente por significar como ato de tirar a própria vida provocado por condição psicológica, ou seja, a FN "depressão" passa a fazer parte da relação de pertinência enunciativa, isto é, da construção de sentidos da FN "suicídio".

Em relação à FN "suicídio", observamos que embora a forma cídio seja pertinente como "morte provocada" a si mesmo, "suicídio" não orienta sentidos de crime suscetível à sanção jurídica, como ocorre com as demais formações nominais.

Líng. e Instrum. Linguíst., Campinas, SP, n. 44, p. 57-77, jul./dez. 2019 
Portanto, ao compor as FNs "homicídio", "infanticídio", e suicídio", a forma -cídio não produz sentidos pela simples descrição de uma realidade extralinguística: "morte de homem", "morte de recém-nascido", "morte voluntária", mas sim pelas razões enunciativas do acontecimento de enunciação, que conforme Dias (2016, p. 37, 38) apresenta

um duplo caráter. De um lado, advém da pertinência enunciativa, isto é, de uma motivação do presente do enunciar. De outro lado, constitui-se pelos referenciais que proporcionam as balizas históricas para significar esse presente contraído pelas pertinências da enunciação.

Na sequência, a rede enunciativa 2 apresenta as FNs "feminicídio", "generocídio", "lesbocídio".

\subsection{Rede enunciativa 2 : feminicídio, generocídio, lesbocídio}

(a) Dois terços dos casos de feminicídio foram cometidos na casa da vítima, segundo pesquisa do Ministério Público Estadual (MPE). Em 58\% dos casos foram usadas armas brancas, como facas, para feri-las ou matá-las. Dos registros, em $75 \%$ a vítima tinha laço afetivo com o agressor. [...] "Vivemos uma doença social, um 'generocídio' motivado por machismo e sentimento de posse", afirma Valéria. (CARVALHO, 2018, p. 13, grifo nosso).

(b) O Ministério Público (MP) do Paraná denunciou ontem o professor de Biologia Luiz Felipe Manvailer pelo crime de feminicídio. Ele é suspeito de jogar a mulher, a advogada Tatiane Spitzner, do quarto andar do prédio onde moravam, [...] A promotoria ressalta que, durante as agressões, o acusado "produziu lesões compatíveis com esganadura (...) praticando tal delito mediante asfixia. A suspeita é de que o professor esganou a mulher e a jogou da janela do apartamento. (O ESTADO DE S. PAULO, 2018, p. 15, grifo nosso).

(c) A sobrinha-neta do ex-presidente da república José Sarney foi estuprada, antes de ser assassinada pelo empresário Lucas Porto, de 37 anos [cunhado], segundo atesta a polícia civil do

Líng. e Instrum. Linguíst., Campinas, SP, n. 44, p. 57-77, jul./dez. 2019 
Maranhão. [...] o assassino confesso vai responder por três crimes: estupro, homicídio e feminicídio. Segundo o secretário de Segurança Jeferson Portela, o crime foi extremamente violento. (O ESTADO DE S. PAULO, 2016, p.19, grifo nosso).

(d) Em abril de 2016, Luana Barbosa dos Reis - uma mulher lésbica, negra, mãe e periférica - morreu após ser espancada por três policiais militares na frente do filho de 14 anos em Ribeirão Preto (SP). A repercussão deste caso de lesbocídio, vinculado ao fato de não existir informações específicas sobre violência contra lésbicas no Brasil, fez com que a estudante de Serviço Social pela UERJ, Milena Carneiro, decidisse criar um projeto para reunir histórias e dados desses crimes. "Eu, enquanto lésbica não feminilizada, sofro agressões por ser lésbica desde que me entendo por gente. Ver o assassinato da Luana me instigou a refletir sobre onde estavam os outros casos", afirma a estudante. (CATRACA LIVRE, 2018, grifo nosso).

A rede enunciativa 2 é integrada por enunciados sobre mortes criminosas de mulheres, e apresenta as FNs "feminicídio", "generocídio", "homicídio" e "lesbocídio" constituídas pela forma cídio, a qual evoca o referencial histórico de "morte provocada".

As ocorrências linguísticas dos enunciados (a), (b) e (c) denunciam especificações comuns ao ato de matar mulheres; proximidade entre o agressor e suas vítimas; natureza violenta atribuída ao comportamento de determinados homens. Essas especificações são marcadas pelas FNs armas brancas, facas, esganadura, asfixia, estuprada, extremamente violento; laço afetivo, marido, cunhado; machismo, sentimento de posse, as quais tomam parte na construção de sentidos da FN "feminicídio". Desse modo, em enunciados que dizem da morte de mulher praticada por homem, a FN "feminicídio" pode estabelecer relações de pertinência com necessidade de proteção e prevenção de crimes contra a mulher; ideologia da superioridade masculina em relação à mulher, entre outros problemas sociais.

$\mathrm{Ou}$ seja, a pertinência enunciativa da FN "feminicídio", relativamente nova na língua portuguesa e não dicionarizada, não se

Líng. e Instrum. Linguíst., Campinas, SP, n. 44, p. 57-77, jul./dez. 2019 
dá pela simples composição "femina +cídio", a pertinência surge na enunciação pela necessidade social. É isso que faz com que o ato de matar mulheres praticado por homens ganhe um nome específico na língua: "feminicídio", o qual vem ganhando força enunciativa para substituir ou mesmo aparecer em inter-relação com a FN "homicídio". Isto é, a forma -cídio adquire nova pertinência enunciativa quando se trata de agregar à base relativa à mulher. A razão enunciativa desse novo enfoque de pertinência se estabelece frente à constituição sóciohistórica do referencial.

Observamos ainda que o enunciado (a) apresenta a FN "generocídio", formada por "gênero+cídio", a qual retoma a FN "feminicídio", devido à necessidade social de especificar enunciativamente mortes motivadas pela condição do gênero feminino, ou seja, não se trata da "morte provocada" do gênero em si, mas sim do que o gênero significa nesse enunciado.

Nessa direção, no enunciado (d), a FN "lesbocídio" formada por "lesbos+cídio" apresenta o referencial histórico de "morte provocada" de mulher homoafetiva. Nesse acontecimento, a FN "lesbocídio" é associada às FNs mulher lésbica, negra, mãe e periférica, lésbica não feminilizada, qualificações que podem manifestar condições de exclusão e exposição à violência. Desse modo, a FN "lesbocídio" é pertinente como ocorrência de linguagem quando é enunciada para nomear morte de mulher praticada por homem, motivada não apenas pelo fato de ser mulher, isto é, pela visão social da superioridade masculina como ocorre em "feminicídio", mas pelo preconceito e discriminação decorrentes da orientação sexual em conjunto com situação econômica, tom de pele e aparência mais ou menos feminina da vítima.

Mortes provocadas por violência doméstica entre casais homoafetivos também recebem o nome de "lesbocídio". No entanto, essa FN ganha pertinência enunciativa na língua em enunciados que demandam necessidade de visibilidade social, leis de proteção específica, conscientização, respeito à diversidade, entre outros.

Desse modo, podemos compreender que "feminicídio", "generocídio" e "lesbocídio" são ocorrências enunciativas pertinentes não apenas como "morte de mulher", "morte de gênero" e "morte de lésbica", mas como novos modos de marcar discursivamente a morte de indivíduos pertencentes às chamadas minorias sociais. Portanto, em

Líng. e Instrum. Linguíst., Campinas, SP, n. 44, p. 57-77, jul./dez. 2019 
conformidade com o que Dias (2013, p. 16) explica sobre a constituição da formação nominal, o funcionamento dessas FNs passa a conjugar

uma potencialidade de observação da realidade, não a partir das eventuais propriedades informativas dos elementos discretos dessa realidade, mas a partir dos traços em função dos quais elementos do real adquirem pertinência para a realidade enunciada, ou seja, em termos foucaultianos, a partir do nível enunciativo da própria formulação.

A seguir, a rede enunciativa (3) apresenta as FNs "sincericídio" e "politicídio".

\subsection{Rede enunciativa 3: sincericídio; politicídio}

(a) "Sincericídio dos apoiadores da Reforma da Previdência: ela vai corrigir a 'injustiça' da empregada doméstica se aposentar antes do que a patroa. O cinismo da Casa Grande não tem limites...", postou Boulos. (FERNANDES, 2019, grifo nosso).

(b) Para o deputado Danilo Forte (PSB), nem todos podem ser punidos por recebimento de dinheiro de propina repassado por partido. Segundo ele, deve haver separação. "A levar dessa maneira, vamos ter um politicídio [...] Todos eram financiados pelas empresas, todas participam desse jogo, eram os mesmo (sic)patrocinadores. Vai condenar todo mundo? Não tem como. Uma coisa é o cara que operou, montou esquema, outra é quem, de boa fé,(sic) participou de campanha", argumentou. (O POVO, 2017, grifo nosso).

No enunciado (a), que diz sobre a reforma da previdência, a FN "sincericídio" é formada por "sinceridade+cídio". Nesse acontecimento enunciativo, a FN "sincericídio" constitui sentidos pelo referencial histórico da forma -cídio, "morte provocada", e pelas relações de pertinência que "sinceridade" produz no acontecimento de enunciação. Nesse sentido, essas relações são constituídas pela

Líng. e Instrum. Linguíst., Campinas, SP, n. 44, p. 57-77, jul./dez. 2019 
captação de enunciados que argumentam sobre a verdade, fidelidade, honestidade, autenticidade, franqueza, entre outras perspectivas que regulam o funcionamento da língua no convívio social.

Assim, no fragmento enunciativo (a): "Sincericídio dos apoiadores da Reforma da Previdência: ela vai corrigir a 'injustiça' da empregada doméstica se aposentar antes do que a patroa”, o qual pode ser reescrito por "é justo que patroa se aposente primeiro do que a empregada", a FN "sincericídio", "morte provocada" da sinceridade, pode ser pertinente como "insinceridade" no sentido de que o dizer do fragmento enunciativo (a) significa como fingimento, dissimulação, falsidade, algo que não deve ser dito, ou ainda como "sinceridade extrema", no sentido de não se importar com a posterioridade do dizer.

Portanto, a pertinência enunciativa da FN "sincericídio" é projetada, nesse acontecimento, conforme o que Dias e Zattar (2017 b, p.1144) argumentam sobre a pertinência, pela "relação entre recortes de memória de significação e a demanda de um presente [que] movimenta as formações articulatórias que constituem a unidade do enunciado, a sua constituição formal". Assim, os recortes de memória evocam os lugares sociais de pertencimento de empregada e patroa, a desigualdade social, bem como a legislação da aposentadoria, atribuindo à FN "sincericídio" pertinência enunciativa de "morte provocada" pela insinceridade/sinceridade extrema, desencadeando relações de sentido de descontentamento dos defensores dos direitos das empregadas domésticas; dos direitos dos mais pobres, entre outros.

O enunciado (b), que aborda a criminalização de propina para partidos políticos, apresenta a FN "politicídio" formada por "político(a) +cídio". Nessa ocorrência, o referencial histórico de cídio, ao se juntar à base político(a), é pertinente como "morte provocada" em razão da relação de sentidos que o político ou a política contrai nesse enunciado.

Desse modo, no fragmento enunciativo (b)

"nem todos podem ser punidos por recebimento de dinheiro de propina repassado por partido. [...] deve haver separação. "A levar dessa maneira, vamos ter um politicídio [...]" (grifo nosso)

Líng. e Instrum. Linguíst., Campinas, SP, n. 44, p. 57-77, jul./dez. 2019 
A pertinência enunciativa de "politicídio" se dá de duas maneiras, a primeira, entre "política+cídio" ao evocar a relação entre partidos políticos e o setor empresarial que aponta para a morte de um modo específico de fazer política, isto é, morte da propina, pela possibilidade de criminalização dessa prática; a segunda, na articulação de "político+cídio", ao remeter à morte do político, pela punição a todos os que, no exercício de um cargo político, se envolvam direta ou indiretamente com a prática política de propina. Desse modo, a FN "politicídio" passa a ser pertinente como "morte da política" e "morte do político" ao significar como finitude e sanção à prática e recepção, de forma ilícita, de dinheiro ou bens materiais.

Em vista disso, Dias e Zattar (2017, p. 1144) argumentam que

o que dizemos mantém relação com um conjunto de outros dizeres com os quais estamos em contato. Nós somos afetados por tudo aquilo que nos rodeia, seja pelo que os outros estão nos dizendo, seja pelo que estamos presenciando, seja pelo que produz alcance nos nossos sentidos, seja pelo que movimenta os nossos desejos, os nossos afetos, seja pelo que achamos que não está certo, pelo que consideramos que seja merecedor de nossa intervenção, seja pelo que achamos que devemos reforçar, elogiar, encorajar, intervir, reprimir, incentivar. E tudo isso é regulado por formas específicas de dizer, modos de se fazer reconhecer pela linguagem.

Portanto, compreendemos que a pertinência enunciativa das FNs "sincericídio" e "politicídio" é determinada pelos modos de funcionamento da linguagem nas práticas sociais.

\section{Considerações finais}

Neste artigo, analisamos, com fundamento no modelo teórico proposto por Dias (2018), FNs constituídas pela forma X-cídio. Consideramos a noção de articulação intranominal, com a qual pudemos observar a formação de palavras ancorada em razões enunciativas, isto é, pelo referencial histórico que projeta diferentes pertinências enunciativas. Nessa direção, entendemos que o

Líng. e Instrum. Linguíst., Campinas, SP, n. 44, p. 57-77, jul./dez. 2019 
referencial histórico da forma -cídio, "morte provocada", enquanto finitude da vida humana ou de outras entidades, adquire pertinência social ao se agregar a diferentes bases na representação x-cídio, tendo em vista o acontecimento de enunciação, o qual pode ser captado em redes enunciativas. Com esse modelo, conseguimos explicar de maneira mais consistente que a formação de palavras envolve mais do que o processo cognitivo, ela se realiza pela observação do processo enunciativo de uso social da língua.

Desse modo, considerando referencial histórico de "morte provocada", observamos nas amostras das redes enunciativas 1 e 2 que as FNs x-cídio "homicídio", "infanticídio", suicídio"; "feminicídio", "generocídio" e "lesbocídio" constituem pertinência como morte humana com diferentes direcionamentos de sentidos, tendo em vista implicações jurídicas, políticas e sociais.

Já na rede enunciativa 3, a forma -cídio projeta nas FNs "sincericídio" e "politicídio" pertinência enunciativa de morte de entidade, considerando que "sinceridade", "política" e "língua" constituem modos de organizar o convívio social pela linguagem. Nesse sentido, essas articulações intranominais representam modos de enunciar ideias e comportamentos, no exercício das práticas sociais dos falantes da língua portuguesa.

Por fim, compreendemos que a perspectiva teórica adotada mostrase relevante para explicar o funcionamento enunciativo da forma cídio, tanto em palavras socialmente assentadas como "homicídio" e "suicídio", como em neologismos, a exemplo de "feminicídio" e "sincericídio", uma vez que essas ocorrências entram na língua pelas razões enunciativas que motivam o seu aparecimento, ou seja, quando fatos sociais adquirem relevância social, como no caso da morte de mulheres em razão da sua condição feminina, os acontecimentos enunciativos, de ordem social, tomam o referencial da forma -cídio, já configurado nas regularidades gramaticais, e incorporam esses focos sociais na língua, tornando-os pertinentes nos nossos enunciados, razão enunciativa para as articulações que criam, por exemplo, feminicídio, de largo uso social no nosso cotidiano.

\section{Referências bibliográficas}

ALMEIDA, M. L. L. de; ANDRADE, K. E; GONÇALVES, C. A. (2010). "Se a macumba é para o bem, então é boacumba: análise

Líng. e Instrum. Linguíst., Campinas, SP, n. 44, p. 57-77, jul./dez. 2019 
morfoprosódica e semântico-cognitiva das substituições sublexicais em português". In: Revista Linguística, v. 6, n.2, p. 1-16. Rio de Janeiro.

BALLY, C. (1947). Linguistique général et linguistique française. 4. ed. Berne: Éditions A. Francke, 1965.

BENVENISTE, E. (1966). Problemas de linguística geral I. Campinas: Pontes, 1988.

(1974). Problemas de Linguística Geral II. Campinas:

Pontes, 1989.

BYBEE, J. (2010). Language, usage and cognition. New York: Cambridge Universety Press.

CARVALHO, M. A. (2018). 2 de cada 3 feminicídios são na casa da vítima.

em: $<$ https://acervo.estadao.com.br/pagina/\#!/20180302-45426-spo-13-mrta13-not/tela/fullscreen $\geq$. Acesso em: 15/03/19.

CATRACA LIVRE, (2018). Thalita Carauta, a Gorete de 'Segundo Sol. Disponível em:< https://catracalivre.com.br/cidadania/thalita-

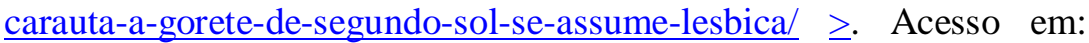
15/03/19.

DIAS, L. F. (2013). "Formações nominais designativas da língua do Brasil: uma abordagem enunciativa". In: Letras, v. 23, n. 46, p. 11-22. Santa Maria: UFSM.

DIAS, L. F.; SILVA, E. E. R. R. da. (2015 a). "Formas nominais designativas na constituição do perfil feminino: uma abordagem enunciativa". In: Revista (Con) Textos Linguísticos, v.9, p. 149-161. Vitória: UFES.

(2015b). "Sentido e enunciação: a atualidade do conceito de acontecimento na semântica". In: Estudos da Língua(gem), v.13, p. 229 - 248. Vitória da Conquista: UESB.

. (2016). "Nomes de cidades de Mato Grosso: uma abordagem enunciativa”. In: KARIM, T. M.; DI RENZO, A. M.; BRESSANIN, J. A.; KARIM, J. M. (orgs.) Atlas dos nomes que dizem histórias das cidades brasileiras: um estudo semântico-enunciativo do Mato Grosso (Fase I). Campinas: Pontes, p. 33-49.

DIAS, L. F.; ZATTAR, N. (2017). "O funcionamento do vocativo: uma abordagem da enunciação". In: Domínios de lingu@gem, v. 11, n. 4, p. 1136-1151. Uberlândia: UFU.

Líng. e Instrum. Linguíst., Campinas, SP, n. 44, p. 57-77, jul./dez. 2019 


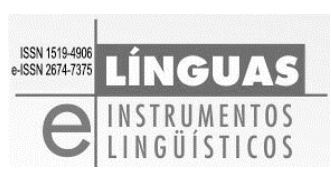

Pontes, 2018.

(2018). Enunciação e relações linguísticas. Campinas:

. (2018b). "Da composição nominal a formação nominal: forma linguística e enunciação". In: AGUSTINI, C. RODRIGUÊS, E. (orgs). Uma vida pela linguagem: homenagem a Émile Benveniste. Campinas: Pontes, p. 247-266.

DUCROT, O. (1981). Provar e dizer: linguagem e lógica. São Paulo: Global.

(1984). "Enunciação". In: Enciclopédia Einaudi: linguagemenunciação, v.2, p. 368-393. Lisboa: Imprensa Nacional/Casa da Moeda.

FERNANDES, A. Nas redes sociais, reforma da Previdência provoca polêmica. (2019).

Disponível

$\mathrm{em}:<$

https://economia.estadao.com.br/noticias/geral,nas-redes-sociaisreforma-da-previdencia-provoca-polemica,70002735115 $>$. Acesso em: 05/04/19.

G1. (2018). Ataque na Catedral: atirador planejava chacina desde $2008 e$ treinava com a arma em casa. Disponível em: $<$ https://g1.globo.com/sp/campinas-

regiao/noticia/2018/12/21/ataque-na-catedral-trecho-de-diario-mostraque-atirador-que-matou-5-previa-crime-desde-2008.ghtml>. Acesso em: 24/02/19.

GONÇALVES, C. A. (2016). Atuais tendências em formação de palavras. São Paulo: Contexto.

GUIMARÃES, E. J. (2005). Semântica do acontecimento. Campinas: Pontes, $2^{\circ}$ ed.

O ESTADO DE S. PAULO, (2016). Assassino estuprou sobrinhaneta de Sarney. Disponivel em:< https://acervo.estadao.com.br/pagina/\#!/20161124-44963-nac-19-mrta20-not/tela/fullscreen $>$. Acesso em: 15/03/19.

O ESTADO DE S. PAULO, (2018). Professor do PR é denunciado por feminicídio Disponível em:< https://acervo.estadao.com.br/pagina/\#!/20180807-45584-spo-15-mrta15-not/tela/fullscreen $\geq$. Acesso em: 15/03/19.

O POVO, (2017). Decisão do Supremo pressiona políticos. Disponível em: $<$ https://www.opovo.com.br/jornal/politica/2017/03/decisao-dosupremo-pressiona-politicos.html >. Acesso em: 05/04/19.

Líng. e Instrum. Linguíst., Campinas, SP, n. 44, p. 57-77, jul./dez. 2019 
REZENDE, P. (2018). Mãe acusada de matar bebê e esconder corpo por 5 anos tem júri popular marcado, em Goiânia. Disponível em:<https://g1.globo.com/go/goias/noticia/mae-acusada-de-matarbebe-e-esconder-corpo-por-5-anos-tem-juri-popular-marcado-emgoiania.ghtml >. Acesso em: 24/02/19.

\section{Palavras-chave: Enunciação, Formas "x-cídio", Articulações linguísticas.}

Keywords: Enunciation, "x-cide" forms, linguistic articulations.

\section{Notas}

* Doutoranda em Estudos Linguísticos na Universidade Federal de Minas Gerais (UFMG).

${ }^{1} \mathrm{O}$ desenvolvimento dessa concepção se inspira no conceito de 'referencial' dado por Foucault (1986, p. 104): “um 'referencial' não é constituído de 'coisas', de 'fatos', de 'realidades', ou de 'seres', mas de leis de possibilidade, de regras de existência para os objetos que aí se encontram nomeados, designados ou descritos, para as relações que aí se encontram afirmadas ou negadas. O referencial do enunciado forma o lugar, a condição, o campo de emergência, a instância de diferenciação dos indivíduos ou dos objetos, dos estados de coisas e das relações que são postas em jogo pelo próprio enunciado; define as possibilidades de aparecimento e de delimitação do que dá à frase seu sentido, à proposição seu valor de verdade. É esse conjunto que caracteriza o nível enunciativo da formulação, por oposição ao seu nível gramatical e seu nível lógico $[\ldots]$ "...

2 Abordar semanticamente uma unidade nominal na perspectiva da formação nominal envolve uma busca das razões enunciativas da condensação de um nome (primeira dimensão da nominalidade), da articulação entre formadores de nomes (segunda dimensão) ou da determinação que o nome recebe nas articulações que ele contrai no âmbito do grupo nominal (terceira dimensão da nominalidade) (DIAS, 2018, p. 126).

${ }^{3}$ Disponível em: <https://www.corpusdoportugues.org/>.

Líng. e Instrum. Linguíst., Campinas, SP, n. 44, p. 57-77, jul./dez. 2019 